\title{
Administração oral de peptídios e proteínas: I. Estratégias gerais para aumento da biodisponibilidade oral
}

\author{
Catarina Silva', António Ribeiro², Domingos Ferreira ${ }^{3}$, Francisco Veiga ${ }^{1 *}$ \\ 'Laboratório de Tecnologia Farmacêutica, Faculdade de Farmácia, Universidade de Coimbra, Coimbra, Portugal, ${ }^{2}$ \\ Laboratório de Tecnologia Farmacêutica, Instituto Superior de Ciências da Saúde do Norte, Gandra, Paredes, ${ }^{3}$ \\ Laboratório de Tecnologia Farmacêutica, Faculdade de Farmácia, Universidade do Porto, Porto, Portugal
}

*Correspondência: Prof. Francisco Veiga Faculdade de Farmácia Universidade de Coimbra 3000 COIMBRA - Portugal E-mail: fveiga@ci.uc.pt
Existem, atualmente, centenas de peptídios e proteinas com ação terapêutica. Os obstáculos inerentes à sua administração oral têm impulsionado a investigação de estratégias capazes de os ultrapassar. Nesta revisão são abordados estes dois aspectos. A microencapsulação, pela sua versatilidade, sobressai entre as demais estratégias, afirmando-se como escolha potencial na administração oral de fármacos peptídicos.

\section{Unitermos:}

- Fármacos peptídicos

- Formulações farmacêuticas

- Inibidores das proteases

- Microencapsulação

- Promotores da absorção

\section{INTRODUÇÃO}

As proteínas e os peptídios podem ser considerados fármacos ideais porque intervêm, essencialmente, em todos os processos biológicos e reações, caracterizando-se por elevada eficiência e potência, ou seja, atuam especificamente e em baixas concentrações. Os desenvolvimentos mais recentes na biotecnologia tornaram possível produção em larga escala de grande variedade de proteínas. Encontram-se, atualmente, comercializadas ou em ensaios clínicos centenas de proteínas com ação terapêutica, incluindo anticorpos monoclonais, enzimas, agentes antimicrobianos, inibidores enzimáticos, vacinas, agentes imunomoduladores, fatores de crescimento, citocinas e hormônios. Por outro lado, a descodificação do genoma humano permitirá trazer ao conhecimento geral novas proteínas, entre as quais algumas terão inevitavelmente aplicações terapêuticas (Burke, 2000; Putney, 1999; Zhou, Li Wan Po, 1991).

Apesar das vantagens terapêuticas das proteínas e dos peptídios, estes agentes não são, de um modo geral, ativos por via oral. A biodisponibilidade oral é reduzida, sobretudo, por rápida e intensa degradação pré-sistémica pelas enzimas proteolíticas e por fraca permeabilidade intestinal face à sua elevada massa molecular (MM) e hidrofilicidade. As baixas biodisponibilidades obtidas conduzem a elevada variabilidade inter e intraindividual na administração de fármacos peptídicos e implicam desperdício elevado de princípio ativo (p.a.) (Sarciaux, Acar, Sado, 1995; Zhou, 1994).

A exigência de administração parenteral acarreta diversos inconvenientes, em particular, a necessidade de repetidas injeções devido ao reduzido tempo de meia-vida de peptídios e proteínas (Burke, 2000) e à possibilidade do aparecimento de efeitos indesejados, como a tromboflebite e a necrose tecidual (Zhou, Li Wan Po, 1991), responsáveis por baixa adesão dos doentes a esta via de administração. Tem-se procurado desenvolver formulações de liberação controlada ou recorrer a outras vias de administração, nomeadamente, oral, bucal, retal, nasal, ocular, vaginal ou transdérmica (Putney, 1999). A via oral é via preferencial devido à facilidade de administração, conveniência e aceitação.

São diversas as estratégias utilizadas para aumentar a biodisponibilidade oral de fármacos peptídicos, nomeadamente, a utilização de inibidores das enzimas proteolíticas, promotores da absorção, modificação química e formulações farmacêuticas específicas, como siste- 
mas de partículas, emulsões, sistemas de liberação targeting e sistemas bioadesivos. Na escolha do método a utilizar, há a considerar o fato de os peptídios serem moléculas de elevada labilidade, que em condições físicoquímicas extremas podem sofrer desnaturação ou agregação com perda da sua atividade (Putney, 1999).

Esta revisão descreve os aspectos associados à administração oral de peptídios e proteínas, bem como as estratégias possíveis a adotar para alcançar esse fim. Numa segunda parte, será abordada a microencapsulação e a sua aplicação neste âmbito e, numa terceira parte, estes vários aspectos serão focados na administração oral da insulina.

\section{OBSTÁCULOS À ADMINISTRAÇÃO ORAL DE PROTEÍNAS E PEPTÍDIOS}

\section{Degradação enzimática pré-sistêmica}

A atividade proteolítica é talvez um dos maiores obstáculos na administração oral de fármacos peptídicos. Em indivíduos normais, 94-98\% do total de proteínas são completamente digeridas e absorvidas. A extensão da degradação protéica é dependente da estrutura do peptídio ou proteína e não é constante nos vários segmentos intestinais (Langguth et al., 1997).

A proteólise tem início no estômago, na presença de pepsina, e prolonga-se no intestino delgado, por ação das enzimas proteolíticas pancreáticas e das peptidases da mucosa intestinal. As proteases pancreáticas mais relevantes são a tripsina, a a-quimotripsina e a elastase, endopeptidases que clivam as ligações peptídicas internas, e as carboxipeptidases A e B, exopeptidases que digerem os fragmentos produzidos pelas enzimas anteriores (Langguth et al., 1997). A atividade enzimática das proteases do lúmen apenas pode ser avaliada tendo em consideração as unidades secretadas pelo pâncreas por minuto (Bernkop-Schnurch, 1998). As peptidases associadas à mucosa intestinal localizam-se em 3 frações subcelulares dos enterócitos: no citosol, nos lisossomas e nas microvilosidades, onde a atividade proteolítica é mais importante. A peptidase mais abundante das microvilosidades é a aminopeptidase $\mathrm{N}$, uma amino-exopeptidase, tal como as aminopeptidases A, W e P, a dipeptidilaminopeptidase IV e a $\gamma$-glutamiltranspeptidase, também presentes, juntamente com endopeptidases (endopeptidase 24.11 e endopeptidase 24.18) e carboxiexopeptidases (carboxipeptidases $\mathrm{P}$ e $\mathrm{M}$ e a enzima de conversão da angiotensina). No citosol, estão presentes enzimas solúveis, sobretudo dipeptidases, uma aminotripeptidase e as prolina-dipeptidases (prolinase e prolidase), que completam a hidrólise intracelular de die tripeptídios transportados ativamente através das microvilosidades por um transportador transmembranar dependente de prótons. Por outro lado, é necessário ter em consideração a microflora presente na zona distal do intestino delgado e no intestino grosso, responsável por variedade de reações metabólicas, como desglicuronidação, descarboxilação, redução de ligações duplas, hidrólise de ésteres ou amidas e desidroxilação (Langguth et al., 1997). A proteólise no cólon é cerca de 20 a 60 vezes mais baixa do que ao nível do íleo e são as enzimas do ecossistema microbiano as principais responsáveis pela atividade proteolítica, embora também exista alguma atividade proteolítica residual das enzimas pancreáticas (Rubinstein et al., 1997).

\section{Fraca permeabilidade}

A passagem através do epitélio intestinal é fundamental para obter disponibilidade sistêmica de um fármaco administrado por via oral. Esta barreira é formada por uma monocamada de células epiteliais (enterócitos, entre outras), que se ligam nas superfícies apicais por junções paracelulares e estão cobertas à superfície por uma camada de muco. Os fármacos podem ultrapassar este obstáculo por transporte transcelular através das células epiteliais, o que inclui a difusão passiva, o transporte ativo ou facilitado, a endocitose e a transcitose, ou por transporte transcelular através das junções paracelulares (Figura 1) (Kolac, Streichhan, Lehr, 1996; Zhou, 1994). Na via transcelular existem duas barreiras, a membrana celular apical e basolateral, enquanto que na via paracelular só existe uma barreira, as junções paracelulares (Kolac, Streichhan, Lehr, 1996).

Os aminoácidos, dipeptídios e tripeptídios são capazes de penetrar na membrana mucosa, pela via transcelular, através de transportadores específicos pre-

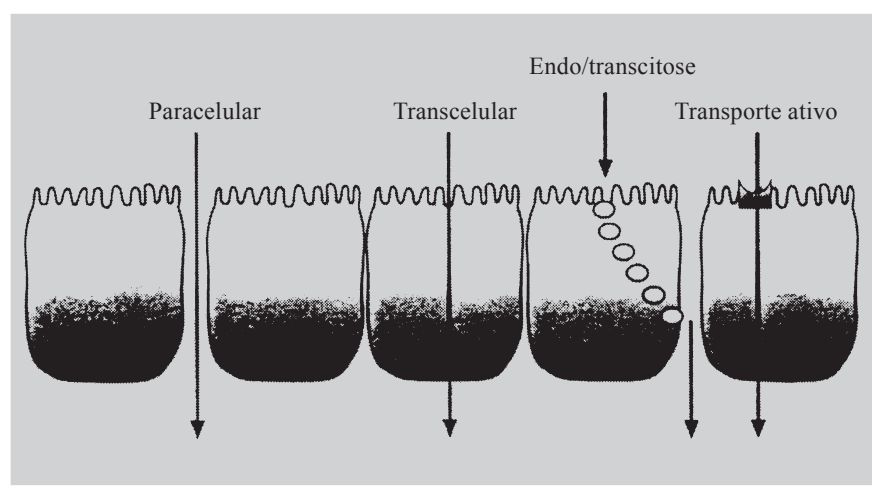

FIGURA 1 - Mecanismos de transporte através das células epiteliais (Adaptado de Kolac, Streichhan, Lehr, 1996) 
sentes no intestino delgado ou por pinocitose (endocitose de fluidos), mas os peptídios maiores e as proteínas são, de um modo geral, impedidos de o fazer (Rouge, Doelker, 1996; Zhou, 1994).

O transporte transcelular depende primariamente das propriedades físico-químicas do fármaco, coeficiente de partição e massa molecular (MM). Limita-se, normalmente, a compostos hidrofóbicos e relativamente pequenos porque é necessária partição do composto entre a membrana apical e a membrana basolateral do epitélio intestinal (Lipka, Crison, Amidon, 1996; Hochman, Artursson, 1994). A pinocitose não é um mecanismo de transporte de contribuição significativa. Contudo, algumas moléculas de maiores dimensões, como os peptídios e as proteínas são absorvidas por este mecanismo, nos enterócitos e nas regíons das placas de Peyer (Rouge, Doelker, 1996). A entrada dos peptídios nos enterócitos, por pinocitose, leva à formação de fagossomas, que se fundem com os lisossomas, permitindo o ataque pelas enzimas presentes nos lisossomas e uma quase completa degradação do seu conteúdo. As células $\mathrm{M}$ das placas de Peyer não contêm lisossomas, apresentando elevado nível de pinocitose, pelo que o transporte de peptídios por pinocitose-exocitose (transcitose), pelas células $M$, pode ser mais eficaz do que através dos enterócitos (Lenaerts, 1996). As placas de Peyer estão localizadas primariamente no íleo e permitem o transporte das macromoléculas para o sistema linfático. A atividade de aminopeptidase ao nível do jejuno e íleo, em coelhos albinos, é apenas cerca de 20-30\% daquela presente nas zonas vizinhas sem placas de Peyer (Hayakawa, Lee, 1992). Embora a sua permeabilidade seja elevada, representa apenas uma pequena percentagem da superfície total da mucosa intestinal, pelo que somente pequenas quantidades de macromoléculas podem ser transportadas (Kolac, Streichhan, Lehr, 1996). Além disso, este pode não ser um bom local para vetorização de fármacos, uma vez que, depois da meia-idade, as placas de Peyer diminuem drasticamente com o envelhecimento (Rouge, Doelker, 1996).

Outro mecanismo para absorção de macromoléculas é a endocitose mediada por receptores, que, à semelhança da pinocitose, não permite o transporte de quantidades elevadas de macromoléculas. Após a ligação do fármaco ao receptor, o complexo formado é internalizado para formar vesículas, que se fundem com os lisossomas citosólicos ou são transportadas através do citosol diretamente para a membrana basolateral (Kolac, Streichhan, Lehr, 1996).

Alternativamente, a passagem das moléculas ocorre através das junções paracelulares entre as células. As junções paracelulares tornam-se progressivamente mais apertadas em direção ao cólon, o que é acompanhado de dimi- nuição da permeabilidade da membrana para os compostos polares (Rouge, Doelker, 1996). A passagem das moléculas através da via paracelular depende da sua forma, tamanho e carga e da seletividade e dimensões da via (Adson et al., 1994). Para avaliar o raio do poro, foi utilizada a monocamada celular Caco-2, uma linha celular de adenocarcinoma do cólon humano, que se diferencia espontaneamente em células representativas do intestino delgado (Hilgers, Conradi, Burton, 1990). Os estudos mais recentes apontam para valores de 4,4 $1,1 \AA$ (Okumu et al., 1997) e de 4,5 $\pm 0,1 \AA$ (Watson, Rowland, Warhurst, 2001). Porém, as propriedades das junções paracelulares nas células da Caco-2 são idênticas às do cólon humano in vivo (Artursson, 1993) e como os espaços paracelulares no intestino delgado são mais permeáveis, a probabilidade de absorção de fármacos peptídicos, nesta regíon, deverá ser superior. No cólon de ratos, o raio do poro foi estimado em 8-9 $\AA$ (Tomita et al., 1988). Embora o grau de permeabilidade das junções paracelulares varie para os diferentes tipos de epitélio, normalmente, as junções paracelulares são impermeáveis a moléculas com um raio superior a 11-15 (Pauletti et al., 1996). Para os peptídios de baixa MM, a carga é seletiva, sendo a permeabilidade superior para os peptídios de carga positiva. Com o aumento da MM, o tamanho torna-se fator mais predominante e o efeito da carga menos significativo (Pauletti, Okumu, Borchardt, 1997).

Formadas por quatro componentes polipeptídicos identificados, as junções paracelulares estão intimamente associadas a um anel de actina-miosina presente no citoplasma epitelial, que, ao se contrair, provoca um relaxamento da estrutura. A abertura das junções paracelulares pode ser causada por diferentes mecanismos, conforme avaliado por diminuição na resistência elétrica transepitelial (transepithelial electrical resistance, TEER), nomeadamente, alteração do estado de fosforilação dos seus componentes por ativadores da proteína quinase A, remoção de AMPc ou depleção de íons cálcio. Outros mecanismos envolvidos incluem a depleção de ATP, a absorção de nutrientes dependente de íons sódio ou alterações gerais na estrutura da actina por oxidantes, ativadores da proteína quinase $\mathrm{C}$, quelantes de íons cálcio, toxina A do Clostridium difficile ou citochalasinas (Hochman, Artursson, 1994). O transporte ativo de glicose e aminoácidos (a.a.) da mucosa intestinal para os espaços laterais intercelulares está acoplado ao transporte de íons sódio, criando uma força osmótica, que desencadeia a contração do anel de actina-miosina perijuncional e o aumento da permeabilidade paracelular (Lee, 1990).

A barreira de muco é igualmente importante para os fármacos peptídicos devido às interações que são estabelecidas. Os fármacos com carga aniônica ou neutra 
apresentam menor interação com a superfície da membrana celular, carregada negativamente (Zhou, 1994). As proteínas com MM superior a $5 \mathrm{KDa}$ só dificilmente conseguem atravessar a camada de muco (Bernkop Schnurch, Fragner, 1996).

\section{Instabilidade química e física}

A natureza físico-química complexa das proteínas, que lhes confere potencial como agentes terapêuticos, também é responsável pela sua fragilidade. A alteração não enzimática das proteínas pode ser de dois tipos: química e física.

A instabilidade química é definida como um processo que modifica a proteína, por clivagem ou formação de ligações covalentes, para originar uma nova entidade química. As alterações químicas incluem a desamidação, oxidação, hidrólise, trocas de dissulfeto, racemização e $\beta$-eliminação (Chen, 1992; Manning, Patel, Borchardt, 1989).

A instabilidade física não envolve a modificação covalente da proteína, podendo ocorrer desnaturação, adsorção à superfície, agregação e precipitação (Manning, Patel, Borchardt, 1989). A desnaturação diz respeito a uma alteração do enrolamento global da molécula, com perda da estrutura terciária e, freqüentemente, da estrutura secundária. Pode ser causada por aumento ou diminuição da temperatura, valores de $\mathrm{pH}$ extremos, adição de solventes orgânicos, agentes desnaturantes (Manning, Patel, Borchardt, 1989), adição de sais, pressão elevada, adsorção à superfície e liofilização (Chen, 1992). O processo pode ser reversível ou irreversível. O desdobramento favorece a ocorrência de outras reações de inativação, como a agregação a outras moléculas protéicas e/ou alterações químicas, o que conduz a perda da atividade biológica, formação de partículas e precipitação (Chen, 1992; Manning, Patel, Borchardt, 1989).

No que respeita à administração oral de fármacos peptídicos, a auto-agregação é de particular importância porque os agregados, de maior dimensão, apresentam menor permeabilidade através da membrana intestinal, além de possível atividade biológica diminuída (Fix, 1996a).

\section{ESTRATÉGIAS PARA AUMENTAR A BIODISPONIBILIDADE ORAL DE PROTEÍNAS E PEPTÍDIOS}

\section{Inibidores das enzimas proteolíticas}

A co-administração de agentes inibidores das enzimas proteolíticas é estratégia possível para o aumento da biodisponibilidade oral de peptídios e proteínas, como foi demonstrado em vários estudos in vivo (Langguth et al., 1997; Kimura et al., 1996; Morishita et al., 1992a). Contudo, a utilização de inibidores enzimáticos em terapias de longa duração, como ocorre freqüentemente com este tipo de fármacos, não é isenta de efeitos adversos importantes. Além dos efeitos tóxicos ao nível sistêmico e danos diretos na mucosa intestinal, os inibidores enzimáticos continuam a ter um potencial tóxico causado pela sua própria ação inibidora. Além de distúrbios na digestão das proteínas, é de se esperar a estimulação da secreção de proteases, devida à regulação por feedback negativo, que pode resultar em hipertrofia e hiperplasia do pâncreas ou até mesmo no desenvolvimento de focos neoplásicos, freqüentemente progressivos para carcinoma invasivo. A redução ou a exclusão deste mecanismo de regulação é possível pelo desenvolvimento de sistemas de administração de fármacos, resultantes da imobilização dos inibidores em matrizes poliméricas mucoadesivas não absorvíveis, que mantenham o inibidor concentrado em área restrita do intestino, onde irá decorrer a liberação e subseqüente absorção do fármaco (Bernkop-Schnurch, 1998).

A seleção dos inibidores das proteases depende do tipo de protease e da sua distribuição subcelular. Quando a principal atividade proteolítica é citosólica é fundamental que os próprios agentes inibidores sejam absorvidos para a célula, o que não é fácil, visto ser estes compostos normalmente demasiado grandes ou hidrofílicos para atravessar as membranas biológicas (Lee, 1990).

Os diversos inibidores enzimáticos das enzimas proteolíticas secretadas para o lúmen (Tabela I) e ligadas às microvilosidades intestinais (Tabela II) podem ser classificados, de acordo com a estrutura química, em quatro categorias (Bernkop-Schnurch, 1998), a seguir descritas.

i. Inibidores que não são baseados em aminoácidos Excetuando poucos casos, esta classe de inibidores tem mais interesse teórico do que prático, já que a maioria é altamente tóxica. Contudo, são inibidores muito potentes e a sua imobilização em matrizes não-absorvíveis ou o desenvolvimento de análogos modificados quimicamente podem reduzir ou até eliminar este inconveniente. Estão incluídos neste grupo o diisopropilfluorofosfato (DFP), o fluoreto de fenilmetilsulfonila (PMSF), o fluoreto de 4-(2-amino-etil)-benzenossulfonato (AEBSF), o cloridrato do fluoreto de (4-aminofenil)-metanossulfonila (APMSF), potentes inibidores das serinaproteases, mas de elevada toxicidade. O mesilato de 4-(4isopropilpiperidinocarbonil)fenil-1,2,3,4-tetraidro-1naftoato (FK-448), o mesilato de camostato e o glicocolato de sódio já apresentam menor toxicidade. 
TABELA I - Inibidores das proteases secretadas no lúmen

\begin{tabular}{lll}
\hline Proteases secretadas no lúmen & Co-factor & Inibidas por \\
\hline Tripsina (EC 3.4.21.4) & Cálcio & $\begin{array}{l}\text { Aprotinina, inibidor de Bowman-Birk, inibidor tripsínico de } \\
\text { soja, mesilato de camostato, inibidores flavonóides, } \\
\end{array}$ \\
& $\begin{array}{l}\text { antipaína, leupeptina, } p \text {-aminobenzamidina, AEBSF, TLCK } \\
\text { (clorometilcetona de tosil-lisina), APMSF, DFP, PMSF, } \\
\text { derivados do poliacrilato }\end{array}$ \\
\hline
\end{tabular}

Quimotripsina (EC 3.4.21.1) Cálcio

Aprotinina, inibidor de Bowman-Birk, inibidor tripsínico de soja, quimostatina, benziloxicarbonil-Pro-Phe-CHO, FK448, ovoinibidor de galinha, complexos de açúcares e ácido bifenilborônico, DFP, PMSF, $\beta$-fenilpropionato, derivados do poliacrilato

\begin{tabular}{lll}
\hline Elastase (EC 3.4.21.36) & Cálcio & $\begin{array}{l}\text { Elastatina, metoxissuccinil-Ala-Ala-Pro-Val-clorometil- } \\
\text { cetona (MPCMK), inibidor de Bowman-Birk, inibidor } \\
\text { tripsínico de soja, ovomucóide de galinha, DPF, PMSF }\end{array}$ \\
\hline Carboxipeptidase A (EC 3.4.17.1) & Zinco & $\begin{array}{l}\text { EDTA, conjugados quitosana-EDTA, derivados do } \\
\text { poliacrilato }\end{array}$ \\
\hline Carboxipeptidase B (EC 3.4.17.2) & Zinco & $\begin{array}{l}\text { EDTA, conjugados de quitosana-EDTA, derivados do } \\
\text { poliacrilato }\end{array}$ \\
\hline
\end{tabular}

(Adaptado de Bernkop-Schnurch, 1998)

ii. Aminoácidos e aminoácidos modificados - De um modo geral, os a.a. modificados são praticamente desprovidos de toxicidade e podem ser produzidos a um custo relativamente baixo. Porém, devido à baixa $\mathrm{MM}$ e à elevada solubilidade são extensivamente diluídos no intestino e rapidamente absorvidos, o que exige grandes quantidades para conseguir um efeito inibidor contra as proteases do lúmen intestinal. Este fato limita o seu interesse na via oral, mas pode ser minimizado em sistemas que garantam a redução ou até a exclusão do efeito de diluição. Os a.a. exibem fraca atividade inibitória contra a aminopeptidase $\mathrm{N}$, o que impulsionou a sua modificação em compostos mais potentes como os derivados do ácido a-aminobórico: boroleucina, boro-valina e boro-alanina. A $N$-acetilcisteína tem um forte efeito inibidor contra a atividade enzimática da aminopeptidase $\mathrm{N}$, sendo promissora na inibição das proteases pela sua baixa toxicidade e propriedades mucolíticas adicionais, que reduzem a barreira de difusão.

iii. Peptídios e peptídios modificados - A bacitracina A, um dodecapeptídio de 1423 Da obtido a partir do Bacillus licheniformis, apresenta grande resistência às enzimas proteolíticas e tem atividade inibitória contra a aminopeptidase N. Além disso, possui efeitos promotores da absorção sem que conduza a danos graves na mucosa intestinal. O grande inconveniente é o seu efeito nefrotóxico, que poderá ser excluído por imobilização em matrizes nãoabsorvíveis. Os dipeptídios e tripeptídios apresentam uma atividade inibitória fraca e não específica contra algumas exopeptidases e, por analogia, com os a.a., a sua atividade inibitória pode ser melhorada por modificação química. $\mathrm{O}$ inibidor fosfinato VI é um inibidor do "estado de transição" com forte atividade contra aminopeptidases. A pepstaína é um pentapeptídio modificado muito potente na inibição da pepsina. Um grupo de peptídios modificados, com uma função aldeído, nomeadamente, a antipaína, leupeptina, quimostatina e elastatinal são inibidores reversíveis e potentes da quimotripsina. Outros peptídios modificados que atuam como inibidores reversíveis incluem a fosforamida, bestatina, puromicina e amastatina.

iv. Polipeptídios - Devido à sua elevada $\mathrm{MM}$, os inibidores das proteases polipeptídicos podem concentrar-se mais facilmente em sistemas de administração baseados em matrizes transportadoras de fármacos. A liberação lenta do inibidor a partir de uma formulação permite a sincronização com a liberação do fármaco polipeptídico e, conseqüentemente, aumento da sua biodisponibilidade. Por esta razão e pela sua baixa toxicidade e forte atividade inibitória, os inibidores polipeptídicos são os agentes auxiliares mais usados para superar a barreira enzimática. A aprotinina é um inibidor básico de 58 a.a., com efeito inibitório da tripsina e 
TABELA II - Inibidores das proteases ligadas às microvilosidades intestinais

\begin{tabular}{lll}
\hline Proteases das microvilosidades & Co-factor(es) & Inibidas por \\
\hline Aminopeptidase N (EC 3.4.11.2) & Zinco, cobalto & $\begin{array}{l}\text { Aminoácidos, di- e tripeptídios, EDTA, amastatina, } \\
\text { bestatina, puromicina, análogos dipeptídicos do ácido } \\
\text { fosfínico, derivados do ácido } \alpha \text {-aminoborônico } \\
\text { conjugados de quitosana-EDTA, glicocolato de sódio }\end{array}$ \\
\hline Aminopeptidase A (EC 3.4.11.7) & Zinco, cálcio & $\begin{array}{l}\text { Análogos dipeptídicos do ácido fosfínico, derivados } \\
\text { do ácido } \alpha \text {-aminoborônico, puromicina, EDTA, 1,10- } \\
\text { fenantrolina }\end{array}$ \\
\hline Aminopeptidase P (EC 3.4.11.9) & Zinco, manganês & $\begin{array}{l}\text { PMSF, bestatina, análogos dipeptídicos do ácido } \\
\text { fosfínico, derivados do ácido } \alpha \text {-aminoborônico }\end{array}$ \\
\hline Aminopeptidase W (EC 3.4.11.16) & Zinco & $\begin{array}{l}\text { Análogos dipeptídicos do ácido fosfínico, derivados } \\
\text { do ácido } \alpha \text {-aminoborônico }\end{array}$ \\
\hline Leucina aminopeptidase (EC 3.4.11.1) & Zinco, magnésio, & $\begin{array}{l}\text { Bestatina, amastatina, análogos dipeptídicos do ácido } \\
\text { fosfínico, inibidores flavonóides, derivados do ácido } \\
\alpha \text {-aminoborônico }\end{array}$ \\
\hline
\end{tabular}

$\overline{\text { Dipeptidil peptidase IV (EC 3.4.14.5) Zinco } \quad \text { Análogos ácido } N \text {-peptidil- } O \text {-acilidroxilamina }}$
borônico da prolina e alanina, DFP

\begin{tabular}{|c|c|c|}
\hline g-glutamil transpeptidase (EC 2.3.2.2) & Magnésio & $\begin{array}{l}\text { Acivicina (ácido amino-(3-cloro-4,5-diidro-isoxazol- } \\
\text { 5-il)-acético), L-serina borato }\end{array}$ \\
\hline Peptidil dipeptidase A (EC 3.4.15.1) & Zinco & $\begin{array}{l}\text { Inibidores da enzima de conversão da angiotensina } \\
\text { (em teoria) }\end{array}$ \\
\hline Carboxipeptidase M (EC 3.4.17.12) & Zinco & $\begin{array}{l}\text { Ácido D,L-2-mercaptometil-3-guanidinoetiltiopro- } \\
\text { panóico }\end{array}$ \\
\hline Carboxipeptidase P (EC 3.4.17.16) & Zinco, manganês & \\
\hline Endopeptidase neutra (EC 3.4.24.11) & Zinco & $\begin{array}{l}\text { 1,10-Fenantrolina, tiorfano (ácido (2-mercaptometil- } \\
\text { 3-fenil-propionilamino)-acético), fosforamido, SQ } \\
28,603 \text { ( } N \text {-(2-(mercaptometil)-1-oxo-3-fenilpropil)- } \\
\beta \text {-alanina) }\end{array}$ \\
\hline
\end{tabular}

Endopeptidase-24.18 (EC 3.4.24.18) Zinco

(Adaptado de Bernkop-Schnurch, 1998)

quimotripsina. O inibidor de Bowman-Birk (71 a.a.) e o inibidor tripsínico de Kunitz (184 a.a.), também conhecido por inibidor tripsínico da soja, inibem a tripsina, a quimotripsina e a elastase. Outros inibidores desta classe incluem o inibidor tripsínico da ovalbumina ou ovomucóide (186 a.a.) e o inibidor tripsínico pancreático humano (56 a.a.).

À parte destas classes químicas de inibidores enzimáticos, encontram-se os agentes complexantes, que devido à sua capacidade em capturar cátions divalentes, cofatores de muitas proteases, podem apresentar atividade inibitória. A inibição da tripsina, quimotripsina e elastase pelos agentes complexantes é dependente da concentração do agente complexante e da concentração de íons cálcio nos fluidos gástrico e intestinal. Os agentes complexantes também podem inibir as exopeptidases dependentes de zinco, tais como, as carboxipeptidases A e B e a aminopeptidase N. Agentes representantes desta classe incluem o EDTA, o EGTA, a 1,10-fenantrolina e a hidroxicolina. Devido à complexação dos cátions divalentes, estes agentes inibitórios apresentam propriedades promotoras de penetração adicionais (Bernkop-Schnurch, 1998).

\section{Promotores da absorção}

Pelo fato de as membranas mucosas serem resistentes à penetração pela maioria dos peptídios e proteínas, a 
co-administração destas com promotores da absorção é alternativa válida. A utilização dos promotores da absorção é limitada pelas freqüentes alterações na mucosa, nomeadamente, a remoção das proteínas da membrana, perda de células, secreção excessiva de muco e ciliotoxicidade, além do risco de toxicidade sistêmica decorrente da absorção destes agentes (Zhou, 1994).

Existem várias teorias para explicar os mecanismos de ação dos promotores de absorção: o aumento da solubilidade por dissociação dos agregados protéicos ou peptídicos (Shao et al., 1994; Touitou et al., 1987), a inibição não-específica das enzimas proteolíticas (Shao et al., 1993), a redução da viscosidade da camada de muco aderente à superfície (Bernkop-Schnurch, Valenta, Daee, 1999) e a diminuição da integridade da membrana mucosa (Schilling, Mitra, 1990; Uchiyama et al., 1999).

Existem quatro grandes tipos de promotores da absorção (Fix, 1996b; Hochman, Artursson, 1994; Shao et al., 1993; Lee, 1990):

1) agentes quelantes - EDTA, EGTA, ácido cítrico, salicilatos, derivados $N$-acil de colágeno e enaminas (derivados $N$-aminoacil de $\beta$-dicetonas);

2) tensoativos - aniônicos (dodecil sulfato de sódio, lauril sulfato de sódio), catiônicos (brometo hexadecil de trimetilamônio), não-iônicos (Tween 80 , polioxietileno20-cetiléter, polioxietileno-(24)-colesterol-éter, polioxietileno-9-lauriléter) e fisiológicos (sais biliares, como desoxicolato sódico, glicocolato sódico e taurocolato sódico e os seus derivados como o taurodiidrofusidato sódico e o glicodiidrofusidato sódico);

3) ácidos graxos - ácido oléico, ácido caprílico e os seus derivados, como as acilcarnitinas (palmitoilcarnitina), acilcolinas e mono- e diglicerídios;

4) não-tensoativos, tais como, uréias cíclicas nãosaturadas e derivados 1-alquil e 1-alquenilazacicloalcanona.

Os quelantes de cálcio aumentam a permeabilidade intestinal por abertura das junções paracelulares num processo mediado pelas proteína quinases. A depleção de íons cálcio não ocorre diretamente nas junções paracelulares, induz alterações globais nas células incluindo ruptura dos filamentos de actina, ruptura das junções aderentes, diminuição da adesão celular e ativação das proteína quinases. Contudo, como a formulação tem apenas acesso à superfície da mucosa e as concentrações do íon cálcio são variáveis, é pouco provável que os quelantes possam ser administrados em quantidade adequada para baixar suficientemente os níveis de íons cálcio, para induzir a abertura das junções paracelulares de um modo rápido, reversível e reprodutível (Hochman, Artursson, 1994).
Os tensoativos interagem com as membranas celulares, aumentando a permeabilidade de um modo dependente da dose. Para baixas concentrações, os tensoativos são incorporados na bicamada lipídica, alterando as propriedades físicas das membranas celulares. Quando a bicamada lipídica fica saturada, formam-se micelas mistas, que causam a remoção dos fosfolipídios das membranas e a solubilização destas (Hochman, Artursson, 1994). Contudo, um aumento da permeabilidade da membrana celular não explica todos os efeitos dos tensoativos, já que o aumento da absorção de peptídios pode ocorrer através das junções paracelulares (Anderberg, Lindmark, Artursson, 1993). A potencial natureza lítica dos tensoativos é um inconveniente, uma vez que o epitélio intestinal fornece uma barreira contra a entrada de toxinas, bactérias e vírus do exterior (Hochman, Artursson, 1994).

Outras formas de promover a absorção oral de peptídios e proteínas consistem na utilização de ciclodextrinas (Shao et al., 1994) e agentes mucolíticos (Bernkop-Schnurch, Valenta, Daee, 1999). Um dos mecanismos mais prováveis para a atuação das ciclodextrinas é a dissociação dos agregados peptídicos (Shao et al., 1994), enquanto que os agentes mucolíticos reduzem a barreira exercida pela camada de muco (Bernkop-Schnurch, Valenta, Daee, 1999). Estes agentes mucolíticos podem atuar por diferentes mecanismos: 1) atividade proteolítica que cliva o núcleo protéico da mucina; 2) quebra das ligações dissulfeto das mucoproteínas em compostos sulfidrila e 3) ação detergente, que quebra as ligações não-covalentes no muco (Bernkop-Schnurch, Valenta, Daee, 1999). As proteases e os compostos sulfidrila são mais eficazes na diminuição da viscosidade do muco do que os detergentes. No entanto, apresentam o inconveniente de serem incompatíveis com alguns fármacos.

Os derivados do ácido poliacrílico e as quitosanas foram sugeridos como nova classe de promotores de absorção, pelo fato de aumentarem o transporte de peptídios através da barreira epitelial. Outras vantagens são: pelo fato de não serem absorvidos devido à sua $M M$, não se esperar toxicidade sistêmica, as suas propriedades bioadesivas e, no caso dos poliacrilatos, proteção contra a degradação proteolítica (Lueben et al., 1994).

\section{Modificação química}

A modificação química de peptídios com conversão em pró-fármacos permite obter compostos mais lipofílicos do que a molécula original. Estes pró-fármacos conferem maior proteção contra a degradação proteolítica e ao mesmo tempo permitem que haja reconversão para os peptídios originais mediante reação espontânea ou 
catalisada por enzimas não-específicas, após a absorção. Este tipo de abordagem tem maior aplicação em fármacos peptídicos com menos de 10 aminoácidos, já que os polipeptídios e proteínas bioativas podem sofrer desnaturação (Zhou, 1994; Bundgaard, 1992).

Os derivados $N$ - $\alpha$-hidroxialquílicos ao nível da ligação peptídica são pró-fármacos normalmente mais resistentes à degradação enzimática do que os respectivos peptídios e, em meio aquoso, são convertidos no peptídio e correspondente aldeído, a uma velocidade dependente do $\mathrm{pH}$. A derivatização do grupo hidroxilo, por exemplo, por esterificação, para obter derivados $N$ - $\alpha$-aciloxialquílicos que são clivados por esterases não específicas, permite aumentar a estabilidade e lipofilicidade (Bundgaard, 1992).

\section{Formulações farmacêuticas}

\section{Sistemas de partículas}

As condições fisiológicas do trato gastrointestinal (GI) obrigam a que os sistemas de partículas obedeçam a dois critérios para serem eficazes na administração oral de fármacos. Primeiro, têm de ser resistentes à degradação no trato GI para conseguirem proteger os fármacos. Segundo, os fármacos encapsulados nas partículas têm de ser absorvidos com elevada eficiência do trato GI para serem terapeuticamente eficazes (Chen, Langer, 1998).

As próprias partículas podem ser eficazmente absorvidas para liberar o fármaco no seu alvo (Chen, Langer, 1998). Foram propostos diferentes mecanismos para explicar a translocação de partículas através do intestino: captação pelas placas de Peyer ou folículos linfóides isolados, captação intracelular (endo/transcitose) e passagem intracelular/ paracelular (Couvreur, Dubernet, Puisieux, 1995).

Após administração oral, a absorção de partículas na mucosa intestinal pode ser realizada através das células $M$ das placas de Peyer, pertencentes ao tecido linfóide associado ao intestino ( $\mathrm{g}$ ut associated lymphoid tissue, GALT), pelos folículos isolados do GALT e também pelos enterócitos. Os fatores que promovem a captação de partículas através do GALT incluem: estabilidade da partícula no lúmen intestinal, diâmetro de partícula inferior a $5 \mathrm{~mm}$ (de preferência inferior a $1 \mathrm{~mm}$ ), ausência de cargas à superfície, hidrofobicidade da partícula e presença de ligantes específicos na partícula (Ex.: lectinas) (Florence, 1997). No que respeita ao tamanho das partículas, cerca de 2-3\% das partículas submicronizadas podem ser absorvidas (Florence, 1997), tendo-se verificado que as partículas com $100 \mathrm{~nm}$ mostram eficiência de captação 15-250 vezes superior às partículas de maior dimensão (Desai et al., 1996) e que as partículas com mais de $10 \mathrm{~mm}$ não são captadas pelas células M (Eldridge et al., 1990). As partículas com menos de $5 \mathrm{~mm}$ são transportadas para os vasos linfáticos eferentes, enquanto que a maioria das partículas com mais de $5 \mathrm{~mm}$ de diâmetro permanecem fixas às placas de Peyer (Eldridge et al., 1990).

Os sistemas de partículas podem subdividir-se em:

- Partículas poliméricas - A incorporação ou encapsulação de peptídios ou proteínas em partículas poliméricas de tamanho inferior ao mícron (nanopartículas) até várias centenas de mícron (micropartículas) deve ter, pelo menos, um efeito: a proteção contra a degradação pelas substâncias presentes no trato GI (Allemann, Leroux, Gurny, 1998). Os polímeros utilizados para administração oral são normalmente biodegradáveis, o que permite proteção no trato GI até as partículas sofrerem erosão ou degradação num certo nível do intestino. No entanto, podem ser utilizadas outras estratégias, como será descrito na segunda parte desta revisão, especialmente, recorrendo a polímeros sensíveis ao $\mathrm{pH}$ ou bioadesivos. As partículas biodegradáveis têm sido muito exploradas no campo da imunização por administração oral, devido ao seu transporte mediado pelas células $\mathrm{M}$ do tecido linfóide associado à mucosa intestinal, onde são induzidas respostas imunológicas locais e/ou sistêmicas (Alpar, Eyles, Williamson, 1998). Porém esta área sai fora do âmbito desta revisão.

- Partículas lipídicas - As partículas lipídicas mais comuns são os lipossomas, vesículas esféricas formadas por bicamadas concêntricas, que rodeiam um núcleo aquoso. Os lipossomas podem transportar fármacos lipossolúveis nas suas bicamadas e simultaneamente fármacos hidrossolúveis nos núcleos aquosos. A sua preparação não exige condições rigorosas, o que minimiza a desnaturação de fármacos peptídicos durante a encapsulação. Porém, a maioria das formulações lipídicas não pode ser usada em administração oral pela sua suscetibilidade à ação dos sais biliares e das fosfolipases intestinais. A ruptura das membranas lipossômicas no trato GI leva à exposição do material encapsulado e, conseqüentemente, à perda das suas funções protetoras (Chen, Langer, 1998). A estabilidade dos lipossomas pode ser aumentada por revestimento com diferentes polímeros, entre os quais, derivados do PEG, cadeias sacarídicas da mucina (Iwanaga et al., 1997), quitosana, polivinilálcool com uma cadeia alquílica longa e ácido poliacrílico com um grupo colesterila (Takeuchi et al., 1996). Os niossomas, outro tipo de partículas lipídicas, são vesículas de lipídios 
sintéticos de natureza não-iônica, desenvolvidas com o objetivo de aumentar a estabilidade e a reproducibilidade dos lipossomas (Handjani-Vila, Vanlerberghe, 1985). Esta forma farmacêutica foi utilizada na administração oral de peptídios (Yoshida et al., 1992). Embora a estabilidade química e física dos niossomas seja baixa, os tensoativos ou lipídios, que os constituem, podem atuar como promotores da absorção e aumentar o fluxo de peptídio através da mucosa intestinal. A fixação das vesículas à parede intestinal ou a própria migração das vesículas contendo o fármaco através da parede intestinal podem explicar o aumento da estabilidade do peptídio encapsulado em niossomas (Yoshida et al., 1992). A preparação de lipossomas polimerizados, nos quais as moléculas de fosfolipídios estão ligadas covalentemente, permitiu melhorar o perfil de liberação de uma proteína em fluídos GI simulados em relação aos lipossomas regulares (Okada, Cohen, Langer, 1995).

- Células - A utilização de membranas de eritrócitos como transportadores de fármacos é vantajosa pela sua biocompatibilidade e volume interno relativamente elevado comparativamente a outros sistemas de micropartículas, permitindo o transporte de elevadas quantidades de fármaco (Juliano, 1987). Este tipo de sistema foi aplicado à administração oral de peptídios com um sucesso significativo (Al Achi, Greenwood, 1998).

\section{Emulsões}

A administração oral de fármacos peptídicos em emulsões pode ser vantajosa por diversas razões. As emulsões óleo em água (o/w) permitem superar a baixa solubilidade aquosa de peptídios lipofílicos, como a ciclosporina, enquanto que as emulsões água em óleo (w/ o) protegem os peptídios hidrofílicos dissolvidos na fase interna contra a destruição enzimática pelos fluidos do trato GI. Neste último caso, a absorção é reduzida porque o fármaco dissolvido permanece envolvido e protegido pela fase oleosa. Porém, na presença de lipases e sais biliares há aumento significativo da absorção motivado pela degradação da fase oleosa (Trenktrog, Muller, Seifert, 1995). As emulsões múltiplas água em óleo em água (w/ o/w) são sistemas vesiculares aquosos constituídos por gotas de óleo dispersas, que, por sua vez, contêm gotas aquosas ainda mais pequenas, nos quais o fármaco é encapsulado na fase interna para ser protegido contra a proteólise (Matsuzawa et al., 1995).

As microemulsões são sistemas quaternários contendo mistura de tensoativo/co-tensoativo, que, quando adicionada a mistura hidrofílica/lipofílica de duas fases, origina sistema termodinamicamente estável, formado por microgotículas com um tamanho inferior a $100 \mathrm{~nm}$. A captação dos fármacos peptídicos, no trato GI, a partir das microemulsões é dependente do tamanho da partícula, tipo de fase lipídica da microemulsão, digestibilidade do lipídio usado, tipo de agentes emulsificantes, $\mathrm{pH}$ e quantidade de fármaco que passa para os enterócitos. A absorção dos peptídios pode ocorrer pelos vasos linfáticos, evitando-se o efeito de primeira passagem, ou, ainda, pelas veias mesentéricas (Sarciaux, Acar, Sado, 1995). Podem formar-se microemulsões utilizando ésteres da ácidos graxos como tensoativos não-iônicos (baixa irritação e elevada estabilidade química) e álcoois de cadeia curta como co-tensoativos (Ho, Hsiao, Sheu, 1996).

\section{Sistemas de liberação targeting}

- Revestimentos entéricos

A liberação dos fármacos peptídicos e protéicos no estômago favorece a sua degradação pelas enzimas e $\mathrm{pH}$ gástricos. O revestimento das formulações com materiais gastro-resistentes, liberando os fármacos ao nível intestinal, permitirá proteção contra essa degradação. Os polímeros poliacrílicos têm sido amplamente utilizados para este propósito, especialmente, os co-polímeros de ácido metacrílico-metilmetacrilato Eudragit ${ }^{\circledR}$ RS1, RS2, L100 e S100 (Carino, Mathiowitz, 1999).

\section{- Liberação específica no cólon}

A proteólise no cólon é mais baixa do que ao nível do íleo. Contudo, o tempo de residência no cólon é cerca de 10 vezes superior e os processos de absorção são mais lentos. Como resultado, a exposição às enzimas proteolíticas é mais prolongada no cólon, mesmo que a atividade seja inferior. O cólon saudável pode ser considerado como um depósito, no qual os nutrientes não absorvidos, e a água, bem como a matéria de excreção, se acumulam por períodos longos. Por esta razão, para algumas moléculas, o cólon comporta-se como um reservatório homogêneo, que proporciona absorção constante de fármaco. Além disso, a baixa taxa de turnover de muco e a baixa sensibilidade a estímulos de secreção fazem do cólon um local mais apropriado para a mucoadesão do que o estômago e jejuno (Rubinstein et al., 1997).

A liberação específica de peptídios e proteínas no cólon pode ser conseguida por intermédio de sistemas à base de polímeros, que apresentam diferentes mecanismos de decomposição. O modo mais simples de conseguir uma libera- 
ção no cólon consiste em utilizar um revestimento entérico estável para os valores de $\mathrm{pH}$ do estômago e do intestino delgado e com espessura suficiente para prevenir a difusão nestas zonas do trato GI. Nos sistemas de liberação controlados pelo tempo (time-clock systems), o fármaco é liberado a intervalo de tempo específico, com base no tempo de trânsito esperado para o sistema atingir o cólon. O tempo que antecede a liberação do fármaco é controlado pela espessura de uma camada hidrofóbica (por exemplo, monoestearato de glicerol ou óleo de rícino) ou de uma camada de um polímero hidrofílico como a hidroxipropilmetilcelulose. Estas duas abordagens não garantem que a liberação se faça especificamente no cólon, devido às grandes variações no tempo de trânsito e pH intestinais, de acordo com a dieta, ingestão de alimentos e motilidade intestinal (Rubinstein et al., 1997; Tozaki et al., 1997).

Alternativamente, é possível recorrer a polímeros azo-biodegradáveis (azopolímeros) e a polissacarídeos. Os azopolímeros são hidrogéis reticulados com grupos azo-aromáticos, que protegem os fármacos nos meios gástrico e intestinal. Quando a formulação chega ao cólon, a microflora local reduz as ligações azo, quebrando a reticulação do filme polimérico, e permite a liberação do fármaco (Tozaki et al., 2001). O grau de entumescimento destes polímeros aumenta proporcionalmente com o $\mathrm{pH}$ no trato GI, sendo mais importante do que a natureza das ligações azo nas características da degradação (Rubinstein et al., 1997).

A utilização de polissacarídeos baseia-se na existência, no cólon, de quantidades significativas de polissacaridases, $\beta$-D-glucosidase, $\beta$-D-galactosidase, amilase, pectinase, xilanase, $\beta$-D-glucosidase e dextranases. Os polissacarídeos utilizados podem ser sintéticos ou naturais e, neste caso, a sua hidrossolubilidade e propriedades entumescentes podem ser reduzidas para que a degradação específica no cólon não seja afetada, mantendo a especificidade das enzimas do cólon para os polímeros. São candidatos a este propósito a pectina, goma de guar, dextranos, amilose e sulfato de condroitina (Rubinstein et al., 1997). A pectina reticulada com cloreto de cálcio forma o pectinato de cálcio, um polímero insolúvel e hidrofílico, que se mostra promissor como transportador de proteínas para liberação no cólon (Sriamornsak, 1998). Os veículos poliméricos, além das suas características de degradação específicas, também deverão ser capazes de proteger o fármaco da proteólise, o que pode ser conseguido por incorporação de inibidores das enzimas proteolíticas na formulação ou por utilização de polímeros inibidores de peptidases, especificamente, os polímeros acrílicos reticulados Carbopol ${ }^{\circledR}$ (carbomer) e polycarbophil. Pela sua elevada entumescência, a dispersão em solução aquo- sa destes polímeros ocorre em poucos minutos, sendo adequado incorporar outros polímeros (hidrofóbicos) de forma a controlar a taxa de erosão e minimizar o efeito na barreira de difusão (Bai, Chang, Guo, 1995).

A quitosana também pode ser útil como veículo de peptídios especificamente para o cólon. A sua desintegração específica poderá ser devida a diminuição do $\mathrm{pH}$ no cólon ascendente, em comparação com o íleo terminal, ou à presença de enzimas bacterianas capazes de degradar o polissacarídeo (Tozaki et al., 1997).

\section{- Transcitose mediada pelo receptor}

A transcitose mediada pelo receptor é uma abordagem eficaz na liberação específica de proteínas e peptídios através de barreiras celulares com a vantagem de, ao contrário dos promotores de absorção, não alterar a estrutura das membranas ou das junções paracelulares. Entre vários receptores, o receptor da transferrina (Tfr) apresenta-se como bom candidato porque a transferrina $(\mathrm{Tf})$ é resistente à digestão tríptica e quimotríptica (Xia, Wang, Shen, 2000). A conjugação de um peptídio com a Tf permite, efetivamente, o transporte através das células epiteliais intestinais (Shah, Shen, 1996).

\section{Sistemas bioadesivos}

A utilização de sistemas bioadesivos na liberação controlada de fármacos aumenta o tempo de permanência do fármaco no local de absorção, diminuindo a frequência de administração, e intensifica o contato com a mucosa epitelial. Esta maior intimidade com a mucosa origina um gradiente de concentração, que favorece a absorção de fármacos pouco solúveis e minimiza a eliminação présistêmica de fármacos suscetíveis à degradação, como os peptídios e as proteínas (Lueben et al., 1994; BernkopSchnurch, 1998; Lehr, 2000).

Os polímeros bioadesivos distinguem-se em dois tipos: aqueles que aderem à camada de muco que cobre o epitélio intestinal, designados por mucoadesivos, e aqueles que aderem especificamente à membrana celular, designados por citoadesivos ou de segunda geração. Os polímeros citoadesivos englobam as lectinas, que interagem especificamente com a membrana celular, sendo independentes do turnover do muco (Lehr, 2000).

Existem duas grandes classes de polímeros mucoadesivos, os derivados aniônicos do ácido poliacrílico e as quitosanas, carregados positivamente (Lehr et al., 1992). Pelo fato de interagirem com a camada de muco, o tempo máximo que estes polímeros podem permanecer ligados ao tecido mucoso intestinal é limitado pelo tempo 
de turnover da camada de muco, que foi estimado entre 47 e 270 minutos (Lehr, 1991). Embora este fator fisiológico seja determinante na eficácia dos sistemas mucoadesivos foram descobertas outras propriedades, mencionadas a seguir, que impulsionam o interesse por estes polímeros.

Os polímeros poliacrílicos, carbômero e policarbofil, têm propriedades inibitórias da atividade proteolítica das enzimas intestinais tripsina, a-quimotripsina, carboxipeptidases A e B e leucina aminopeptidase citosólica. Esta ação não é compartilhada pelas quitosanas (Lueben et al., 1996; Lueben et al., 1997). A principal razão apontada para este efeito inibitório são as fortes propriedades complexantes de catíons bivalentes, como os íons $\mathrm{Ca}^{2+}$ e $\mathrm{Zn}^{2+}$, cofatores das enzimas inibidas. Esta complexação é dependente do $\mathrm{pH}$, aumentando para valores de $\mathrm{pH}$ compreendidos entre 4 e 6 (Lueben et al., 1996). A atividade inibitória da degradação proteolítica de fármacos peptídicos, no cólon, também foi atribuída à capacidade dos polímeros poliacrílicos em reduzir o $\mathrm{pH}$ do lúmen (Bai, Chang, Guo, 1995). Os conjugados de quitosana-EDTA exibem propriedades mucoadesivas e também apresentam um efeito inibitório da atividade enzimática de proteases dependentes de $\mathrm{Zn}^{2+}$, como a aminopeptidase $\mathrm{N}$ e carboxipeptidase A, devido à capacidade de complexação com catíons multivalentes (Bernkop-Schnurch, 1998).

Por outro lado, ambas as classes de polímeros mostraram-se capazes de promover o transporte paracelular. Os derivados poliacrílicos, provavelmente, atuam por depleção de íons de $\mathrm{Ca}^{2+}$ extracelular (Borchard et al., 1996), enquanto que as quitosanas promovem a abertura das junções paracelulares devido à interação dos seus grupos amino, carregados positivamente, com grupos siálicos, carregados negativamente, das glicoproteínas ligadas à membrana (Artursson et al., 1994). A indução do transporte paracelular é mais acentuada com a quitosana, mas a atividade protetora contra a degradação proteolítica exibida pelo policarbofil faz com que o efeito final, no aumento do transporte de fármacos peptídicos através do tecido intestinal, seja semelhante para os dois polímeros (Lueben et al., 1997).

Os alginatos também possuem propriedades mucoadesivas, que mostraram ser superiores às do poliestireno, quitosana, carboximetilcelulose e ácido polilático (Chickering, Jacob, Mathiowitz, 1992; Chickering, Mathiowitz, 1995). Devido aos seus grupos carboxílicos, os alginatos são classificados como polímeros mucoadesivos aniônicos (Gombotz, Wee, 1998).

\section{Combinação de estratégias}

A combinação de diferentes estratégias é prática comum para obter maior biodisponibilidade oral de fármacos peptídicos e protéicos. É freqüente combinar estratégias, que permitam ultrapassar simultaneamente as barreiras intestinais enzimática e física, como por exemplo, a combinação de um inibidor enzimático e um promotor da absorção (Geary, Schlameus, 1993) ou a incorporação de inibidores das enzimas proteolíticas e/ou promotores de absorção em partículas poliméricas (Morishita et al., 1992b), emulsões (Suzuki et al., 1998) ou sistemas de liberação no cólon (Hosny et al., 1998).

O efeito inibitório da atividade proteolítica exercido pelos polímeros mucoadesivos, especificamente, derivados poliacrílicos e quitosana-EDTA, pode ser melhorada pela ligação covalente a inibidores enzimáticos (Bernkop-Schnurch, 1998). As propriedades mucoadesivas dos polímeros conjugados não são influenciadas pelas modificações químicas. A imobilização dos inibidores em matrizes não-absorvíveis permite um contato mais íntimo e prolongado com a membrana intestinal, o que apresenta vantagens: diminuição da distância entre o sistema de administração e a membrana absorvente, minimizando a eliminação pré-sistêmica do fármaco polipeptídico; concentração dos inibidores ligados covalentemente no sistema de liberação evitando o efeito de diluição e, conseqüentemente, os distúrbios na digestão das proteínas nutritivas e os efeitos tóxicos sistêmicos e redução da quantidade de inibidor co-administrado por exclusão dos efeitos de diluição (Bernkop-Schnurch, 1998).

\section{ESCOLHA DE UMA ESTRATÉGIA}

As abordagens que permitem proteger peptídios e proteínas contra a proteólise (Tabela III) incluem:

- co-administração de inibidores das proteases,

- modificação química da molécula de fármaco para reduzir a ação proteolítica das enzimas presentes no trato GI,

- encapsulação em pequenas partículas ou utilização de emulsões que transportem o fármaco até ao local de absorção,

- incorporação do fármaco em sistemas bioadesivos, que aumentem o contato entre o sistema de administração e o local de absorção,

- liberação específica em locais do trato GI com menor atividade enzimática (liberação no cólon, revestimento entérico).

Por outro lado, as estratégias capazes de promover a absorção através da mucosa intestinal incluem:

- co-administração de promotores como os sais biliares ou outros agentes capazes de abrir as junções paracelulares, 
- modificação química da molécula de fármaco para aumentar a sua lipofilicidade,

- encapsulação em partículas poliméricas ou lipossomas que promovam a absorção através das junções paracelulares ou por endocitose,

- inclusão do fármaco em sistemas bioadesivos, que aumentem o tempo de contato entre o fármaco e o local de absorção,

- utilização de microdispersões lipídicas para tirar partido da via transcelular de transporte de lipídios e

- liberação targeting em locais de maior absorção (transcitose mediada pelo receptor).

De menos relevo que a proteção contra a proteólise ou a promoção da absorção é a diminuição da instabilidade química e física do fármaco, que pode ser conseguida pela co-administração de determinados promotores, especificamente, os tensoativos, ou por modificação química da molécula.

A probabilidade de aumentar a biodisponibilidade oral de um fármaco peptídico pode aumentar pela combinação das diferentes estratégias apresentadas, mas também se houver métodos, que, simultaneamente, protejam contra a degradação e promovam a absorção. A microencapsulação, sendo um método versátil para administrar fármacos, enquadra-se nesta última situação. A versatilidade resulta das técnicas de preparação e polímeros utilizados, o que permite que para cada molécula de fármaco possa existir um processo de formulação adequado. Por outro lado, a microencapsulação também pode ser combinada com praticamente qualquer outra estratégia (inibidores da proteólise, promotores da absorção, modificação química, sistemas de liberação targeting, sistemas bioadesivos), aumentando as hipóteses de eficácia.

\section{CONCLUSÃO}

Os fármacos peptídicos assumem papel importante como agentes terapêuticos no controle de diversas doenças, que, muitas vezes, requerem tratamentos prolongados. A administração oral é, pela facilidade de aplicação, conveniência e aceitação, via privilegiada, mas a sua potencial utilidade está dependente, sobretudo, da superação das barreiras enzimática e física presentes nas vias de administração não-parenteral. A combinação de várias estratégias, atuando simultaneamente para circunscrever as barreiras à absorção, poderá ser vantajosa. A microencapsulação, que é inerentemente uma combinação de estratégias, mostra-se uma alternativa válida, pois as micropartículas protegem os fármacos da degradação proteolítica e, dependendo da natureza das partículas utilizadas (tipo de polímero, tamanho, adjuvantes), estes sistemas podem também promover a absorção de peptídios e proteínas por diferentes mecanismos. A combinação da microencapsulação com outras estratégias também é possível. Na segunda parte desta revisão, serão descritos os diversos métodos de microencapsulação e a sua aplicação na administração oral de peptídios e proteínas.

\section{ABSTRACT}

\section{Oral delivery system for peptides and proteins: $I$. Approaches to improve oral bioavailability}

There are hundreds of peptides and proteins clinically relevant. The difficulties associated with their oral administration have been responsible for the major efforts in developing ways to improve oral bioavailability. Both

TABELA III - Obstáculos passíveis de serem ultrapassados pelas várias estratégias

\begin{tabular}{lccc}
\hline Estratégia & $\begin{array}{c}\text { Proteção } \\
\text { contra a } \\
\text { proteólise }\end{array}$ & $\begin{array}{c}\text { Promoção } \\
\text { da absorção }\end{array}$ & $\begin{array}{c}\text { Diminuição das } \\
\text { instabilidades } \\
\text { química e física }\end{array}$ \\
\hline Inibidores das proteases & $\bullet$ & $\bullet$ & $\bullet$ \\
Promotores da absorção & $\bullet$ & $\bullet$ & $\cdot$ \\
Modificação química & $\bullet$ & $\bullet$ \\
Encapsulação em sistemas de partículas & $\bullet$ & \\
Emulsões & $\bullet$ & \\
Liberação no cólon & $\bullet$ & $\bullet$ \\
Revestimento entérico & & $\bullet$ \\
Transcitose mediada pelo receptor & $\bullet$ & \\
Sistemas bioadesivos &
\end{tabular}


these subjects are described in this review. The potentiality of microencapsulation presents this technique as a privileged approach for the oral delivery of peptide and protein drugs.

UNITERMS: Absorption enhancer. Formulation. Microencapsulation. Peptide drugs. Protease inhibitors.

\section{REFERÊNCIAS BIBLIOGRÁFICAS}

ADSON, A., RAUB, T. J., BURTON, P. S., BARSUHN, C. L., HILGERS, A. R. Quantitative approaches to delineate paracellular diffusion in cultured epithelial cell monolayers. J. Pharm. Sci., Washington, v. 83, p. 1529-1536, 1994.

AL ACHI, A., GREENWOOD, R. Erythrocytes as oral delivery systems for human insulin. Drug Dev. Ind. Pharm., New York, v. 24, p. 67-72, 1998.

ALLEMANN, E., LEROUX, J. C., GURNY, R. Polymeric nano- and microparticles for the oral delivery of peptides and peptidomimetics. Adv. Drug Deliv. Rev., Amsterdam, v. 34, p. 171-189, 1998.

ALPAR, H. O., EYLES, J. E., WILLIAMSON, E. D. Oral and nasal immunization with microencapsulated clinically relevant proteins. STP Pharma. Sci., Paris, v. 8 , p. 31-39, 1998.

ANDERBERG, E. K., LINDMARK, T., ARTURSSON, P. Sodium caprate elicits dilatations in human intestinal tight junctions. Pharm. Res., Stuttgart, v. 10, p. 857-864, 1993.

ARTURSSON, P. Cell cultures as models for intestinal peptide transport. STP Pharma. Sci., Paris, v. 3, p. 5-10, 1993.

ARTURSSON, P., LINDMARK, T., DAVIS, S. S., ILLUM, L. Effect of chitosan on the permeability of monolayers of intestinal epithelial cells (Caco-2). Pharm. Res., Stuttgart, v. 11, p. 1358-1361, 1994.

BAI, J. P., CHANG, L. L., GUO, J. H. Effects of polyacrylic polymers on the lumenal proteolysis of peptide drugs in the colon. J. Pharm. Sci., Washington, v. 84, p. 12911294, 1995.

BERNKOP SCHNURCH, A., FRAGNER, R. Investigations into difusion behaviour of polypeptides in native intestinal mucus with regard to their peroral administration. Pharm. Sci., v. 2, p. 361, 1996.
BERNKOP-SCHNURCH, A. The use of inhibitory agents to overcome the enzymatic barrier to perorally administered therapeutic peptides and proteins. J. Control Release, Amsterdam, v. 52, p. 1-16, 1998.

BERNKOP-SCHNURCH, A., VALENTA, C., DAEE, S. M. Peroral polypeptide delivery. A comparative in vitro study of mucolytic agents. Arzneimittelforschung, Aulendorf, v. 49, p. 799-803, 1999.

BORCHARD, G., LUEBEN, H. L., DE BOER, A. G., VERHOEF, J. C., LEHR, C.-M., JUNGINGER, H. E. The potencial of mucoadhesive polymers in enhancing intestinal peptide drug absorption. III: Effects of chitosanglutamate and carbomer on epithelial tight junctions in vitro. J. Controlled Release, Amsterdam, v. 39, p. 131138, 1996.

BUNDGAARD, H. The utility of the prodrug approach to improve peptide absorption. J. Controlled Release, Amsterdam, v. 21, p. 63-72, 1992.

BURKE, P. A. Controlled release protein therapeutics: Effects of process and formulation on stability. In: WISE, D. L., ed. Handbook of pharmaceutical controlled release technology. New York: Marcel-Dekker, 2000. p. 661-692.

CARINO, G. P., MATHIOWITZ, E. Oral insulin delivery. Adv. Drug Deliv. Rev., Amsterdam, v. 35, p. 249-257, 1999.

CHEN, H., LANGER, R. Oral particulate delivery: status and future trends. Adv. Drug Deliv. Rev., Amsterdam, v. 34, p. 339-350, 1998.

CHEN, T. Formulation concerns of protein drugs. Drug Dev. Ind. Pharm., New York, v. 18, p. 1311-1354, 1992.

CHICKERING, D. E., JACOB, P., MATHIOWITZ, E. A tensile technique to evalute the interaction of bioadhesive microspheres with intestinal mucosa. Proc. Int. Symp. Control Release Bioact. Mater., v. 19, p. 88-89, 1992.

CHICKERING, D. E., MATHIOWITZ, E. Bioadhesive microspheres: I. A novel electrobalance-based method to study adhesive interactions between individual microspheres and intestinal mucosa. J. Controlled Release, Amsterdam, v. 34, p. 251-261, 1995. 
COUVREUR, P., DUBERNET, C., PUISIEUX, F. Controlled drug delivery with nanoparticles: current possibilities and future trends. Eur. J. Pharm. Biopharm., Stuttgart, v. 41, p. 2-13, 1995.

DESAI, M. P., LABHASETWAR, V., AMIDON, G. L., LEVY, R. J. Gastrointestinal uptake of biodegradable microparticles: effect of particle size. Pharm. Res., Stuttgart, v. 13, p. 1838-1844, 1996.

ELDRIDGE, J. H., HAMMOND, C. J., MEULBROEK, J. A., STAAS, J. K., GILlEY, R. M., TICE, T. R. Controlled vaccine in the gut-associated lymphoid tissues. I. Orally administered biodegradable microspheres target the payer's patches. J. Controlled Release, Amsterdam, v. 11, p. 205-214, 1990.

FIX, J. A. Oral controlled release technology for peptides: status and future prospects. Pharm. Res., Stuttgart, v. 13, p. 1760-1764, 1996a.

FIX, J. A. Strategies for delivery of peptides utilizing absorption-enhancing agents. J. Pharm. Sci., Washington, v. 85, p. 1282-1285, 1996 b.

FLORENCE, A. T. The oral absorption of micro- and nanoparticulates: neither exceptional nor unusual. Pharm. Res., Stuttgart, v. 14, p. 259-266, 1997.

GEARY, R. S., SCHLAMEUS, H. W. Vancomycin and insulin used as models for oral delivery of peptides. $J$. Controlled Release, Amsterdam, v. 23, p. 65-74, 1993.

GOMBOTZ, W. R., WEE, S. F. Protein release from alginate matrices. Adv. Drug Deliv. Rev., Amsterdam, v. 31, p. 267-285, 1998.

HANDJANI-VILA, R. M., VANLERBERGHE, G. Les niosomes. In: BURI, P., PUISIEUX, F., DOELKER, E., BENOIT, J. P., eds. Formes pharmaceutiques nouvelles. Aspects technologique, biopharmacentique \& medical. Paris: Tecnique et documentation (Lavoisier), 1985. p. 561-575.

HAYAKAWA, E., LEE, V. H. L. Aminopeptidase activity in the jejunal and ileal Peyer's patches of the albino rabbit. Pharm. Res., Stuttgart, v. 9, p. 535-540, 1992.

HILGERS, A. R., CONRADI, R. A., BURTON, P. S. Caco2 cell monolayers as a model for drug transport across the intestinal mucosa. Pharm. Res., Stuttgart, v. 7, p. 902910, 1990.
HO, H. O., HSIAO, C. C., SHEU, M. T. Preparation of microemulsions using polyglycerol fatty acid esters as surfactant for the delivery of protein drugs. J. Pharm. Sci., Washington, v. 85, p. 138-143, 1996.

HOCHMAN, J., ARTURSSON, P. Mechanisms of absorption enhancement and tight junction regulation. $J$. Controlled Release, Amsterdam, v. 29, p. 253-267, 1994.

HOSNY, E. A., KHAN GHILZAI, N. M., AL NAJAR, T. A., ELMAZAR, M. M. Hypoglycemic effect of oral insulin in diabetic rabbits using $\mathrm{pH}$-dependent coated capsules containing sodium salicylate without and with sodium cholate. Drug Dev. Ind. Pharm., New York, v. 24, p. 307311,1998

IWANAGA, K., ONO, S., NARIOKA, K., MORIMOTO, K., KAKEMI, M., YAMASHITA, S., NANGO, M., OKU, N. Oral delivery of insulin by using surface coating liposomes: improvement of stability of insulin in GI tract. Int. J. Pharm., Amsterdam, v. 157, p. 73-80, 1997.

JULIANO, R. L. Microparticulate drug carriers: liposomes, microspheres, and cells. In: ROBINSON, J. R., LEE, V. H. L., eds. Controlled drug delivery. Fundamentals and applications. New York: Marcel-Dekker, 1987. p. 555580.

KIMURA, T., SATO, K., SUGIMOTO, K., TAO, R., MURAKAMI, T., KUROSAKI, Y., NAKAYAMA, T. Oral administration of insulin as poly(vinyl alcohol)-gel spheres in diabetic rats. Biol. Pharm. Bull., Tokyo, v. 19, p. 897-900, 1996.

KOLAC, C., STREICHHAN, P., LEHR, C. M. Oral bioavailability of proteolytic enzymes. Eur. J. Pharm. Biopharm., Stuttgart, v. 42, p. 222-232, 1996.

LANGGUTH, P., BOHNER, V., HEIZMANN, J., MERKLE, H. P., WOLFFRAM, S., AMIDON, G. L., YAMASHITA, S. The challenge of proteolytic enzymes in intestinal peptide delivery. J. Controlled Release, Amsterdam, v. 46, p. 39-57, 1997.

LEE, V. H. L. Protease inhibitors and penetration enhancers as approaches to modify peptide absorption. $J$. Controlled Release,Amsterdam, v. 13, p. 213-223, 1990. 
LEHR, C.-M. An estimate of turnover time of intestinal mucus gel layer in the rat in situ loop. Int. J. Pharm., Amsterdam, v. 70, p. 235-240, 1991.

LEHR, C.-M. Lectin-mediated drug delivery: the second generation of bioadhesives. J. Controlled Release, Amsterdam, v. 65, p. 19-29, 2000.

LEHR, C.-M., BOUWSTRA, J. A., SCHACHT, E. H., JUNGINGER, H. E. In vitro evaluation of mucoadhesive properties of chitosan and some other natural polymers. Int. J. Pharm., Amsterdam, v. 78, p. 43-48, 1992.

LENAERTS, V. Systems for the oral delivery of peptides Proc. Formulation of poorly-available drugs for oral administration. Paris, 1996. p. 59-65.

LIPKA, E., CRISON, J., AMIDON, G. L. Transmembrane transport of peptide type compounds: prospects for oral delivery. J. Controlled Release, Amsterdam, v. 39, p. 121-129, 1996.

LUEBEN, H. L., LEEUW, B. J., PÉRARD, D., LEHR, C.M., DE BOER, A. G., VERHOEF, J. C., JUNGINGER, H. E. Mucoadhesive polymers in peroral peptide drug delivery. I. Influence of mucoadhesive excipients on the proteolytic activity of intestinal enzymes. Eur J. Pharm. Sci., Amsterdam, v. 4, p. 117-128, 1996.

LUEBEN, H. L., LEHR, C.-M., RENTEL, C.-O., NOACH, A. B. J., DE BOER, A. G., VERHOEF, J. C., JUNGINGER, H. E. Bioadhesive polymers for the peroral delivery of peptide drugs. J. Control Release, Amsterdam, v. 29, p. 329-338, 1994.

LUEBEN, H. L., RENTEL, C.-O., KOTZE, A. F., LEHR, C.M., DE BOER, A. G., VERHOEF, J. C., JUNGINGER, H. E. Mucoadhesive polymers in peroral peptide drug delivery. IV. Polycarbophil and chitosan are potent enhancers of peptide transport across intestinal mucosae in vitro. J. Controlled Release, Amsterdam, v. 45, p. 1523, 1997.

MANNING, M. C., PATEL, K., BORCHARDT, R. T. Stability of protein pharmaceuticals. Pharm. Res., Stuttgart, v. 6, p. 903-918, 1989.

MATSUZAWA, A., MORISHITA, M., TAKAYAMA, K., NAGAI, T. Absorption of insulin using water-in-oil-inwater emulsion from an enteral loop in rats. Biol. Pharm. Bull., Tokyo, v. 18, p. 1718-1723, 1995.
MORISHITA, I., MORISHITA, M., TAKAYAMA, K., MACHIDA, Y., NAGAI, T. Hypoglycemic effect of novel oral microspheres of insulin with protease inhibitor in normal and diabetic rats. Int. J. Pharm., Amsterdam, v. 78, p. 9-16, 1992a.

MORISHITA, M., MORISHITA, I., TAKAYAMA, K., MACHIDA, Y., NAGAI, T. Novel oral microspheres of insulin with protease inhibitor protecting from enzymatic degradation. Int. J. Pharm., Amsterdam, v. 78, p. 1-7, 1992 b.

OKADA, J., COHEN, S., LANGER, R. In vitro evaluation of polymerized liposomes as an oral drug delivery system. Pharm. Res., Stuttgart, v. 12, p. 576-582, 1995.

OKUMU, F. W., PAULETTI, G. M., VANDER VELDE, D. G., SIAHAAN, T. J., BORCHARDT, R. T. Effect of restrcited conformational flexibility on the permeation of model hexapeptides across Caco-2 cell monolayers. Pharm. Res., Stuttgart, v. 14, p. 169-175, 1997.

PAULETTI, G. M., GANGWAR, S., KNIPP, G. T., NERURKAR, M. M., OKUMU, F. W., TAMURA, K., SIAHAAN, T. J., BORCHARDT, R. T. Structural requirements for intestinal absorption of peptide drugs. $J$. Controlled Release, Amsterdam, v. 41, p. 3-17, 1996.

PAULETTI, G. M., OKUMU, F. W., BORCHARDT, R. T. Effect of size and charge on the passive diffusion of peptides across Caco-2 cell monolayers via the paracellular pathway. Pharm. Res., Stuttgart, v. 14, p. 164-168, 1997.

PUTNEY, S. D. Advances in protein drug delivery. Pharmaceutical News, v. 6, 1999.

ROUGE, N., DOELKER, E. Drug absorption sites in the gastrointestinal tract and dosage forms for site-specific delivery. Int. J. Pharm., Amsterdam, v. 136, p. 117-139, 1996.

RUBINSTEIN, A., TIROSH, B., BALUOM, M., NASSAR, T., FRIEDMAN, M., ET AL. Rationale for peptide drug delivery to the colon and the potential of polymeric carriers as effective tools. J. Controlled Release, Amsterdam, v. 46, p. 59-73, 1997.

SARCIAUX, J. M., ACAR, L., SADO, P. A. Using microemulsion formulations for oral drug delivery of therapeutic peptides. Int. J. Pharm., Amsterdam, v. 120, p. 127-136, 1995. 
SCHILLING, R. J., MITRA, A. K. Intestinal mucosal transport of insulin. Int. J. Pharm., Amsterdam, v. 62, p. 53-64, 1990.

SHAH, D., SHEN, W. C. Transcellular delivery of an insulintransferrin conjugate in enterocyte-like Caco-2 cells. $J$. Pharm. Sci., Washington, v. 85, p. 1306-1311, 1996.

SHAO, Z., LI, Y., CHERMAK, T., MITRA, A. K. Cyclodextrins as mucosal absorption promoters of insulin. Part 2. Effects of beta-cyclodextrin derivatives on alpha-chymotryptic degradation and enteral absorption of insulin in rats. Pharm. Res., Stuttgart, v. 11, p. 11741179, 1994.

SHAO, Z., LI, Y., KRISHNAMOORTHY, R., CHERMAK, T., MITRA, A. K. Differential effects of anionic, cationic, nonionic, and physiologic surfactants on the dissociation, alpha-chymotryptic degradation, and enteral absorption of insulin hexamers. Pharm. Res., Stuttgart, v. 10, p. 243251, 1993.

SRIAMORNSAK, P. Investigation of pectin as a carrier for oral delivery of proteins using calcium pectinate gel beads. Int. J. Pharm., Amsterdam, v. 169, p. 213-220, 1998.

SUZUKI, A., MORISHITA, M., KAJITA, M., TAKAYAMA, K., ISOWA, K., CHIBA, Y., TOKIWA, S., NAGAI, T. Enhanced colonic and rectal absorption of insulin using a multiple emulsion containing eicosapentaenoic acid and docosahexaenoic acid. $J$. Pharm. Sci., Washington, v. 87, p. 1196-1202, 1998.

TAKEUCHI, H., YAMAMOTO, H., NIWA, T., HINO, T., KAWASHIMA, Y. Enteral absorption of insulin in rats from mucoadhesive chitosan-coated liposomes. Pharm. Res., Stuttgart, v. 13, p. 896-901, 1996.

TOMITA, M., SHIGA, M., HAYASHI, M., AWAZU, S. Enhancement of colonic drug absorption by the paracellular permeation route. Pharm. Res., Stuttgart, v. 5, p. 341-346, 1988.

TOUITOU, E., ALHAIQUE, F., FISHER, P., MEMOLI, A., RICCIERI, F. M., SANTUCCI, E. Prevention of molecular self-association by sodium salicylate: Effect on insulin and 6-carboxyfluorescein. J. Pharm. Sci., Washington, v. 76, p. 791-793, 1987.
TOZAKI, H., KOMOIKE, J., TADA, C., MARUYAMA, T., TERABE, A., SUZUKI, T., YAMAMOTO, A., MURANISHI, S. Chitosan capsules for colon-specific drug delivery: improvement of insulin absorption from the rat colon.J. Pharm. Sci., Washington, v. 86, p. 1016-1021, 1997.

TOZAKI, H., NISHIOKA, J., KOMOIKE, J., OKADA, N., FUJTA, T., MURANISHI, S., KIM, S. I., TERASHIMA, H., YAMAMOTO, A. Enhanced absorption of insulin and $(\operatorname{Asu}(1,7))$ eel-calcitonin using novel azopolymer-coated pellets for colon-specific drug delivery. J. Pharm. Sci., Washington, v. 90, p. 89-97, 2001.

TRENKTROG, T., MULLER, B. W., SEIFERT, J. In vitroinvestigation into the enhancement of intestinal peptide absorption by emulsion systems. Eur. J. Pharm. Biopharm., Stuttgart, v. 41, p. 284-290, 1995.

UCHIYAMA, T., SUGIYAMA, T., QUAN, Y. S., KOTANI, A., OKADA, N., FUJITA, T., MURANISHI, S., YAMAMOTO,A. Enhanced permeability of insulin across the rat intestinal membrane by various absorption enhancers: their intestinal mucosal toxicity and absorption-enhancing mechanism of n-lauryl-beta-D-maltopyranoside. J. Pharm. Pharmacol., London, v. 51, p. 1241-1250, 1999.

WATSON, C. J., ROWLAND, M., WARHURST, G. Functional modeling of tight junctions in intestinal cell monolayers using polyethylene glycol oligomers. Am. J. Physiol. Cell Physiol., v. 281, p. C388-C397, 2001.

XIA, C. Q., WANG, J., SHEN, W. C. Hypoglycemic effect of insulin-transferrin conjugate in streptozotocin-induced diabetic rats. J. Pharmacol. Exp. Ther., Baltimore, v. 295, p. 594-600, 2000.

YOSHIDA, H., LEHR, C.-M., KOK, W., JUNGINGER, H. E., VERHOEF, J. C., BOUWSTRA, J. A. Niossomes for oral delivery of peptide drugs. J. Controlled Release, Amsterdam, v. 21, p. 145-154, 1992.

ZHOU,X. H. Overcoming enzymatic and absorption barriers to nonparenterally administered protein and peptide drugs. $J$. Controlled Release, Amsterdam, v. 29, p. 239-252, 1994.

ZHOU, X. H., LI WAN PO, A. Peptide and protein drugs: I. Therapeutic applications, absorption and parenteral administration. Int. J. Pharm., Amsterdam, v. 75, p. $97-$ $115,1991$. 